\title{
Chemotherapy Delays Are Associated with Inferior Outcome in Acute Lymphoblastic Leukemia: A Retrospective Study from a Tertiary Cancer Center in South India
}

\author{
Vineet Agrawal ${ }^{1}$ Smita Kayal ${ }^{2}$ Prasanth Ganesan ${ }^{2} \quad$ Biswajit Dubashi \\ 1Department of General Medicine, Jawaharlal Institute of \\ Postgraduate Medical Education and Research, Puducherry, India \\ ${ }^{2}$ Department of Medical Oncology, Jawaharlal Institute of \\ Postgraduate Medical Education and Research, Puducherry, India

\begin{abstract}
Address for correspondence Smita Kayal, MD, DM, Department of Medical Oncology, Jawaharlal Institute of Postgraduate Medical Education and Research, Dhanvantari Nagar 605006, Puducherry, India (e-mail: kayalsmita@gmail.com).
\end{abstract}

Ind J Med Paediatr Oncol 2021;42:51-60.

\begin{abstract}
Keywords

- acute lymphoblastic leukemia

- delay

- relapse

- survival

- treatment interruption
\end{abstract}

Background Treatment protocols for acute lymphoblastic leukemia (ALL) have evolved over time to give excellent cure rates in children and moderate outcomes in adults; however, little is known how delays in chemotherapy affect long-term survival. Objectives To find the association of delays during different treatment phases on the survival outcomes.

Materials and Methods Data from 149 ALL cases treated between 2009 and 2015 were retrospectively analyzed. Treatment course in commonly used protocols was divided into three phases-induction, consolidation (postremission), maintenance, and also a combined intensive phase (induction plus consolidation) for the purpose of analysis, and delay in each phase was defined based on clinically acceptable breaks. Analysis was done to find the impact of treatment delay in each phase on the survival outcomes.

Results The median age was 12 years (range, 1-57). Multi-center Protocol-841 (MCP-841) was used for 72\%, German Multicenter Study Group for Adult ALL (GMALL) for 19\%, and Berlin, Frankfurt, Muenster, 95 protocol (BFM-95) for $9 \%$ of patients. Delay in induction was seen in $52 \%$, consolidation in $66 \%$, and during maintenance in $42 \%$ of patients. The median follow-up was 41 months, and 3-year survival outcomes for the entire cohort were event-free survival (EFS)-60\%, relapse-free survival (RFS) $-72 \%$, and overall survival (OS) $-68 \%$. On univariate analysis, delay in induction adversely affected EFS (hazard ratio $[H R]=1.78, p=0.04$ ), while delay in intensive phase had significantly worse EFS and RFS (HR $=2.41[p=0.03]$ and $\mathrm{HR}=2.57[p=$ 0.03], respectively). On separate analysis of MCP- 841 cohort, delay in intensive phase affected both EFS $(H R=3.85, p=0.02)$ and RFS $(H R=3.42, p=0.04)$, whereas delay in consolidation significantly affected OS with $(H R=4.74, p=0.04)$ independently.

Conclusion Treatment delays mostly in intensive phase are associated with worse survival in ALL; attempts should be made to maintain protocol-defined treatment intensity while adequately managing toxicities.
DOI https://doi.org/ 10.1055/s-0041-1729513 ISSN 0971-5851
(C) 2021. Indian Society of Medical and Paediatric Oncology

This is an open access article published by Thieme under the terms of the Creative Commons Attribution-NonDerivative-NonCommercial-License, permitting copying and reproduction so long as the original work is given appropriate credit. Contents may not be used for commercial purposes, or adapted, remixed, transformed or built upon. (https://creativecommons.org/licenses/by-nc-nd/4.0/).

Thieme Medical and Scientific Publishers Pvt. Ltd. A-12, 2nd Floor, Sector 2, Noida-201301 UP, India 


\section{Introduction}

Acute lymphoblastic leukemia (ALL) is the most common childhood cancer worldwide; it is relatively less common in adults. Contemporary series from India and other developing countries report overall outcomes far removed from Western figures. Whereas the long-term survival reported from high-income countries for pediatric ALL is close to $90 \%{ }^{1}$ and for adult ALL is $40 \%,{ }^{2}$ the corresponding survival is 60 and $22 \%$, respectively, in studies from India. ${ }^{3-6}$ The inferior outcomes in adults can be attributed mainly to adverse biologic features, along with the inability to tolerate chemotherapy, particularly in older adults. Some of the important factors for inferior outcomes in developing countries are delayed presentation, higher infections, poor social support system, inadequate treatment facilities, and treatment abandonment.

In addition, another important cause of poorer outcome can be delay and interruptions in chemotherapy delivery. ALL is treated with chemotherapy protocols spanning 2 to 3 years, with intensive therapy in the first few months.

In the course of this long treatment period, delays in chemotherapy administration and dose modifications commonly occur due to drug-related toxicity, infections, associated comorbidities, or patient noncompliance. Delaying chemotherapy due to toxicity is safer for patients in the short term, but its long-term impact on survival outcomes is not well established. While the need for dose-intense chemotherapy in curing ALL is well described, there is scant literature describing risk factors for and outcomes after chemotherapy delays in different phases. ${ }^{7-9}$ In this study, we aim to evaluate whether delays in chemotherapy increase the risk of relapse or affect survival in patients undergoing treatment for ALL.

\section{Materials and Methods}

\section{Patient Recruitment}

All patients diagnosed and treated during May 2009 to December 2015 in the Department of Medical Oncology of a tertiary cancer center in Southern India were enrolled in the study. Baseline demographic features, clinical characteristics, disease parameters, treatment details and timelines, toxicities, and outcomes were collected retrospectively from medical case records. Cases with a diagnosis of lymphoblastic lymphoma, with insufficient documentation, or patients who had event (death or discharge against medical advice) before the start of chemotherapy, were excluded from the study. Institutional ethical committee approval for waiver of consent was obtained prior to conducting this study.

\section{Treatment Protocol}

Treatment protocol for ALL generally consists of multiagent chemotherapy in different schedules and combinations and is typically divided into three phases: induction, consolidation, and maintenance, along with central nervous system (CNS) prophylaxis during the first two phases. Induction and consolidation are intensive phases consisting of a combination of eight to ten chemotherapy drugs that are delivered intravenously or orally typically over a period of 4 to
6 months, with the first month being the induction phase. Orally delivered 6-mercaptopurine (6-MP) and methotrexate form the backbone of maintenance phase that continues for 18 to 24 months in different protocols. As per our department policy, Multi-center Protocol-841 (MCP-841) ${ }^{10}$ was used for all cases up to 25 years of age and German Multicenter Study Group for Adult ALL (GMALL) protocol ${ }^{11}$ for adults above 25 years, until 2014. From 2015 onward, in an attempt to move to a high-dose methotrexate-based modern protocol for pediatric and young adult patients, we started using Berlin, Frankfurt, Muenster, 95 protocol (BFM-95) ${ }^{12}$ initially for cases of T cells ALL (T-ALL) $\leq 25$ years.

\section{Definition for Treatment Delay in Different Phases}

As the total treatment spans over 2 to 3 years, the primary objective of the study was to evaluate the effect of prolonged treatment delays on survival outcomes. The time duration between first presentation to the hospital and date of start of chemotherapy (first dose of steroid) was taken as the "delay in initiation" of therapy. For evaluation of delay during ongoing treatment, duration of a particular phase was taken as the difference in dates between the initiation of the particular phase and the start of the next phase of treatment. Each of the three regimens used in our study (MCP-841, GMALL, and BFM-95) were divided into an induction phase, a consolidation phase (postremission), and a maintenance phase. Each of the protocols has a 28-day standard induction phase. Taking into consideration small interruptions due to delay in logistics and staffing or administrative practices, delays due to toxicities, time needed for performing bone marrow exam, and time required for recovery of counts after therapy, a duration of 35 days in induction was classified as "no delay." Durations of 36 to 42 days of induction were classified as "mild delay" and 43 or more days were classified as "severe delay" for descriptive purposes. For analysis, a cutoff of 42 days was taken, and survival outcomes were compared for two groups: patients with duration $<42$ days against those with duration $>42$ days. Only patients who were started on consolidation after completion of induction were evaluated for delay in induction phase.

For MCP-841, the standard duration of consolidation phase is 16 weeks, and of maintenance phase is 21 months. Again taking into consideration small interruptions, durations of 20 weeks for consolidation (4 weeks over standard) and 22 months for maintenance ( 1 month over standard) were considered as acceptable. Using these durations as cutoffs, survival outcomes were analyzed for patients treated with MCP-841. On the other hand, for BFM-95/GMALL protocols, the standard duration of consolidation phase is 28 weeks, and of maintenance phase is 24 months. Again taking into consideration small interruptions, durations of 32 weeks for consolidation (4 weeks over standard) and 25 months for maintenance (1 month over standard) were considered as acceptable. Using these durations as cutoffs, survival outcomes were compared for patients treated with BFM-95/GMALL protocols. Irrespective of the protocol, only patients who completed consolidation phase were evaluated for delay in consolidation. Similarly, only patients with a 
documented date of completion of maintenance phase were evaluated for maintenance delay.

For analysis, a combined duration of induction and consolidation phase was taken as "intensive phase." For MCP-841, the cutoff taken was 26 weeks ( 42 days induction +20 weeks consolidation) and for GMALL/ BFM-95, the cutoff taken was 38 weeks (42 days induction +32 weeks consolidation). The causes for interruptions in chemotherapy were also recorded.

\section{Definition of Survival Outcomes}

Delay in individual treatment phases was evaluated for association with the following survival outcomes: event-free survival (EFS), relapse-free survival (RFS), and overall survival (OS). EFS was defined as the duration from start of induction-phase chemotherapy to occurrence of any event (relapse or death from any cause). RFS was defined as the duration from attainment of complete remission (CR) to relapse. Patients dying without documented relapse were censored in the evaluation of RFS. OS was defined as the duration from the start of induction chemotherapy to death from any cause. Data for survival analysis were censored on May 31, 2018.

\section{Statistical Analysis}

Descriptive statistics were used to summarize baseline characteristics, and treatment timelines. Chi-squared test was used to find association between the baseline parameters and delay in induction phase. Kaplan-Meier survival analysis followed by univariate log rank test was used to compare the survival outcomes in different groups of patients. Univariate and multivariate Cox regression analysis was used to evaluate factors affecting survival outcomes. All statistical analyses were performed by using $5 \%$ level of significance, and $p<0.05$ was taken as statistically significant. For descriptive analysis and survival estimates, IBM SPSS Statistics for Windows, Version 20.0, IBM Corp, Armonk, New York, United States, was used.

\section{Results}

\section{Baseline Characteristics}

Out of 168 patients of ALL registered in our department from 2009 to 2015, 149 met the inclusion criteria. The baseline characteristics of the patients are shown in - Table 1 . The median age was 12 years (range, 1-57), with a male: female ratio of 1.86 . MCP-841 was used for $72 \%, 19 \%$ patients were treated with GMALL, and 9\% with BFM-95 protocols. The median white cell count at presentation was $16 \times 10^{9} / \mathrm{L}$, while 29\% $(n=44)$ had baseline leukocyte count of $>50 \times 10^{9} / \mathrm{L}$. Baseline CNS involvement was present in 13 patients (9\%) and testicular involvement in 2 (1.3\%).

\section{Duration of Treatment Phases and Reasons for Delay}

The duration of chemotherapy phases of induction, consolidation, intensive phase (combined induction and consolidation), and maintenance in different treatment protocols is shown in - Table 2. Delay in initiation of induction therapy of $>7$ days after presentation to hospital was seen in $64 \%$
Table 1 Baseline characteristics $(n=149)$

\begin{tabular}{|c|c|}
\hline Characteristics at diagnosis & $n(\%)$ \\
\hline \multicolumn{2}{|l|}{ Age (y) } \\
\hline $0-14$ & $85(57)$ \\
\hline $15-39$ & $45(30)$ \\
\hline $40-60$ & $19(12)$ \\
\hline Median age (range) & $12(1-57)$ \\
\hline \multicolumn{2}{|l|}{ Sex } \\
\hline Male & $97(65)$ \\
\hline Female & $52(35)$ \\
\hline \multicolumn{2}{|l|}{$\operatorname{TLC}\left(\times 10^{9} / \mathrm{L}\right)$} \\
\hline$<50$ & $100(67)$ \\
\hline$>50$ & $44(29.5)$ \\
\hline Unknown & $5(3.5)$ \\
\hline \multicolumn{2}{|l|}{ Blasts } \\
\hline$<50 \%$ & $40(27)$ \\
\hline$>50 \%$ & $100(67)$ \\
\hline Unknown & $9(6)$ \\
\hline \multicolumn{2}{|l|}{ Sub-type } \\
\hline B-ALL & $101(68)$ \\
\hline T-ALL & $48(32)$ \\
\hline \multicolumn{2}{|l|}{ Risk } \\
\hline Standard & $52(35)$ \\
\hline High & $97(65)$ \\
\hline \multicolumn{2}{|l|}{ Involvement } \\
\hline None & $133(89)$ \\
\hline CNS & $13(9)$ \\
\hline Testis & $2(1.3)$ \\
\hline Both & $1(0.7)$ \\
\hline \multicolumn{2}{|l|}{ Karyotype } \\
\hline Normal & $104(70)$ \\
\hline $\mathrm{Ph}+$ & $6(4)$ \\
\hline Complex & $13(9)$ \\
\hline Unknown & $26(17)$ \\
\hline \multicolumn{2}{|l|}{ Protocol } \\
\hline MCP-841 & $107(72)$ \\
\hline GMALL & $28(19)$ \\
\hline BFM-95 & $14(9)$ \\
\hline
\end{tabular}

Abbreviations: ALL, acute lymphoblastic leukemia; B-ALL, B cells ALL; BFM95, Berlin, Frankfurt, Muenster, 95 protocol; CNS, central nervous system; GMALL, German Multicenter Study Group for Adult ALL; MCP-841, Multicenter Protocol-841; T-ALL, T cells ALL; TLC, total leukocyte count.

patients; however, this delay was not associated with survival outcome (data not shown). Induction duration of $>42$ days was observed in $52 \%(n=70)$ of patients in all the three protocols combined. On analysis of baseline factors affecting induction delay, pediatric age group of 0 to 14 years was found to have significantly higher delay though mild 
54 Chemotherapy Delays Are Associated with Inferior Outcome in ALL Agrawal et al.

Table 2 Duration of phases of chemotherapy

\begin{tabular}{|c|c|c|c|c|}
\hline Outcome parameters & Total $(n)$ & Duration, median (range) & Categories & $n(\%)$ \\
\hline \multirow[t]{2}{*}{ Delay in initiation (d) } & 147 & $9.0(0-101)$ & $\leq 7 \mathrm{~d}$ & $53(36.1)$ \\
\hline & & & $>7 \mathrm{~d}$ & $94(63.9)$ \\
\hline \multirow[t]{3}{*}{ Duration of induction ${ }^{\mathrm{a}}(\mathrm{d})$} & 134 & $43.0(29-87)$ & $\leq 35 \mathrm{~d}$ & $9(7)$ \\
\hline & & & $36-42 d$ & $55(41)$ \\
\hline & & & $>42 d$ & $70(52)$ \\
\hline \multicolumn{5}{|l|}{ Duration of consolidation ${ }^{\mathrm{a}}$} \\
\hline \multirow[t]{2}{*}{ MCP 841} & 93 & $22.3(14.1-31.0)$ & $<20$ wk & $27(29)$ \\
\hline & & & $>20 \mathrm{wk}$ & $66(71)$ \\
\hline \multirow[t]{2}{*}{ GMALL } & 19 & $31.9(22.3-36.9)$ & $<32$ wk & $11(57.9)$ \\
\hline & & & $>32 \mathrm{wk}$ & $8(42.1)$ \\
\hline \multirow[t]{2}{*}{ BFM 95} & 5 & $31.4(24.4-39.7)$ & $<32$ wk & $3(60)$ \\
\hline & & & $>32 \mathrm{wk}$ & $2(40)$ \\
\hline \multicolumn{5}{|l|}{ Duration of maintenance ${ }^{a}$} \\
\hline \multirow[t]{2}{*}{ MCP 841} & 72 & $21.95(20.1-29.4)$ & $<22 \mathrm{mo}$ & $37(51.4)$ \\
\hline & & & $>22 \mathrm{mo}$ & $35(48.6)$ \\
\hline \multirow[t]{2}{*}{ GMALL } & 10 & $23.55(6.5-25.4)$ & $<25 \mathrm{mo}$ & $9(90)$ \\
\hline & & & $>25 \mathrm{mo}$ & $1(10)$ \\
\hline \multirow[t]{2}{*}{ BFM 95} & 3 & $23.8(22.2-24.1)$ & $<25$ mo & $3(100)$ \\
\hline & & & $>25 \mathrm{mo}$ & 0 \\
\hline
\end{tabular}

Abbreviations: ALL, acute lymphoblastic leukemia; BFM-95, Berlin, Frankfurt, Muenster-95 protocol; GMALL, German Multicenter Study Group for Adult ALL; MCP-841, Multi-center Protocol-841.

ancludes patients only if they have completed the respective phase of chemotherapy.

Table 3 Overall outcome $(n=149)$

\begin{tabular}{|c|c|c|c|c|}
\hline Outcome & MCP-841 $(n=107)$ & GMALL $(n=28)$ & BFM-95 $(n=14)$ & Total $(n=149)$ \\
\hline No event & 69 & 12 & 5 & 86 \\
\hline Event & 38 & 16 & 9 & 63 \\
\hline Induction death & 5 & 5 & 2 & 12 \\
\hline Relapse & 25 & 8 & 5 & 38 \\
\hline In consolidation & 1 & 1 & 4 & 6 \\
\hline In maintenance & 17 & 6 & 1 & 24 \\
\hline During follow-up & 7 & 1 & 0 & 8 \\
\hline $\begin{array}{l}\text { Died without documented } \\
\text { relapse }\end{array}$ & 8 & 3 & 2 & 13 \\
\hline \multicolumn{5}{|l|}{ EFS (\%) } \\
\hline At $3 y$ & 67.1 & 44.4 & 29.5 & 59.6 \\
\hline At $5 y$ & 60.2 & 37.0 & - & 53.3 \\
\hline \multicolumn{5}{|l|}{ RFS (\%) } \\
\hline At $3 y$ & 77.1 & 64.0 & 45.9 & 72.7 \\
\hline At $5 \mathrm{y}$ & 69.1 & 53.3 & - & 64.9 \\
\hline \multicolumn{5}{|l|}{ OS (\%) } \\
\hline At $3 y$ & 74.5 & 53.1 & 44.5 & 68.0 \\
\hline At $5 \mathrm{y}$ & 72.8 & 53.1 & - & 66.6 \\
\hline
\end{tabular}

Abbreviations: ALL, acute lymphoblastic leukemia; BFM-95, Berlin, Frankfurt, Muenster-95 protocol; EFS, event-free survival; GMALL, German Multicenter Study Group for Adult ALL; MCP-841, Multi-center Protocol-841; OS, overall survival; RFS, relapse-free survival. 
Table 4 Cox regression survival analysis: entire cohort $(n=149)$

\begin{tabular}{|c|c|c|c|c|c|c|c|c|}
\hline \multirow[t]{2}{*}{ Parameters } & \multirow[t]{2}{*}{ Categories } & \multirow[t]{2}{*}{$n$} & \multicolumn{2}{|l|}{ EFS } & \multicolumn{2}{|l|}{ RFS } & \multicolumn{2}{|l|}{ OS } \\
\hline & & & $\mathrm{HR}(95 \% \mathrm{Cl})$ & $p$-Value & $\mathrm{HR}(95 \% \mathrm{Cl})$ & $p$-Value & $\mathrm{HR}(95 \% \mathrm{Cl})$ & $p$-Value \\
\hline \multicolumn{9}{|l|}{ Univariate analysis } \\
\hline \multirow[t]{3}{*}{ Age $(y)$} & $0-14$ & 85 & 1 & & 1 & & 1 & \\
\hline & $15-39$ & 45 & $\begin{array}{l}1.345 \\
(0.75-2.40)\end{array}$ & 0.318 & $\begin{array}{l}0.984 \\
(0.45-2.14)\end{array}$ & 0.97 & $\begin{array}{l}1.358 \\
(0.69-2.65)\end{array}$ & 0.369 \\
\hline & $40-60$ & 19 & $\begin{array}{l}3.632 \\
(1.91-6.88)\end{array}$ & $<0.001^{\circ}$ & $\begin{array}{l}3.15 \\
(1.33-7.42)\end{array}$ & 0.009 & $\begin{array}{l}3.231 \\
(1.52-6.85)\end{array}$ & 0.002 \\
\hline Sex & Male & 97 & 1 & & 1 & & 1 & \\
\hline \multirow[t]{3}{*}{ TLC $(\times 109 / \mathrm{L})(n=144)$} & Female & 52 & $\begin{array}{l}0.573 \\
(0.32-1.01)\end{array}$ & 0.55 & $\begin{array}{l}0.43 \\
(0.19-0.94)\end{array}$ & 0.035 & $\begin{array}{l}0.755 \\
(0.40-1.41)\end{array}$ & 0.38 \\
\hline & $<50$ & 100 & 1 & & 1 & & 1 & \\
\hline & $>50$ & 44 & $\begin{array}{l}1.958 \\
(1.17-3.26)\end{array}$ & $0.01^{*}$ & $\begin{array}{l}1.754 \\
(0.97-3.18)\end{array}$ & 0.064 & $\begin{array}{l}2.700 \\
(1.41-5.16)\end{array}$ & 0.003 \\
\hline \multirow[t]{2}{*}{ Subtype } & B-ALL & 101 & 1 & & 1 & & 1 & \\
\hline & T-ALL & 48 & $\begin{array}{l}1.423 \\
(0.85-2.38)\end{array}$ & 0.178 & $\begin{array}{l}1.346 \\
(0.69-2.63)\end{array}$ & 0.385 & $\begin{array}{l}1.805 \\
(1.01-3.22)\end{array}$ & 0.046 \\
\hline \multirow[t]{2}{*}{ Risk } & Standard & 52 & 1 & & 1 & & 1 & \\
\hline & High & 97 & $\begin{array}{l}2.594 \\
(1.42-4.71)\end{array}$ & $0.002^{*}$ & $\begin{array}{l}2.294 \\
(1.11-4.73)\end{array}$ & 0.024 & $\begin{array}{l}2.714 \\
(1.34-5.49)\end{array}$ & 0.005 \\
\hline \multirow[t]{2}{*}{ Delay in induction ${ }^{a}(\mathrm{~d})$} & $\leq 42$ & 64 & 1 & & 1 & & 1 & \\
\hline & $>42$ & 70 & $\begin{array}{l}1.780 \\
(1.01-3.14)\end{array}$ & $0.047^{*}$ & $\begin{array}{l}1.657 \\
(0.86-3.18)\end{array}$ & 0.128 & $\begin{array}{l}1.834 \\
(0.92-3.65)\end{array}$ & 0.084 \\
\hline \multirow[t]{2}{*}{ Delay in consolidationa } & No delay & 39 & 1 & & 1 & & 1 & \\
\hline & Delay seen & 78 & $\begin{array}{l}1.892 \\
(0.88-4.05)\end{array}$ & 0.101 & $\begin{array}{l}1.924 \\
(0.86-4.32)\end{array}$ & 0.113 & $\begin{array}{l}2.976 \\
(0.96-9.20)\end{array}$ & 0.058 \\
\hline \multirow[t]{2}{*}{ Delay in intensive phase ${ }^{a}$} & No delay & 37 & 1 & & 1 & & 1 & \\
\hline & Delay seen & 80 & $\begin{array}{l}2.413 \\
(1.05-5.55)\end{array}$ & $0.038^{*}$ & $\begin{array}{l}2.572 \\
(1.05-6.29)\end{array}$ & 0.039 & $\begin{array}{l}2.762 \\
(0.89-8.58)\end{array}$ & 0.079 \\
\hline \multirow[t]{2}{*}{ Delay in maintenance ${ }^{\mathrm{a}}$} & No delay & 49 & 1 & & 1 & & 1 & \\
\hline & Delay seen & 36 & $\begin{array}{l}0.95 \\
(0.25-3.56)\end{array}$ & 0.95 & $\begin{array}{l}0.962 \\
(0.26-3.59)\end{array}$ & 0.954 & $\begin{array}{l}1.378 \\
(0.19-10.09)\end{array}$ & 0.753 \\
\hline \multicolumn{9}{|l|}{ Multivariate analysis } \\
\hline \multirow[t]{2}{*}{ Age (y) } & $0-14$ & 85 & 1 & & 1 & & & \\
\hline & $15-39$ & 45 & $\begin{array}{l}0.813 \\
(0.36-1.82)\end{array}$ & 0.616 & $\begin{array}{l}1.07 \\
(0.46-2.47)\end{array}$ & 0.876 & $\begin{array}{l}0.552 \\
(0.17-1.75)\end{array}$ & 0.313 \\
\hline \multirow[t]{3}{*}{ TLC $(\times 109 / \mathrm{L})(n=144)$} & $40-60$ & 19 & $\begin{array}{l}3.179 \\
(1.28-7.89)\end{array}$ & 0.013 & $\begin{array}{l}3.80 \\
(1.36-10.56)\end{array}$ & 0.011 & $\begin{array}{l}3.30 \\
(1.07-10.12)\end{array}$ & 0.037 \\
\hline & $\leq 50$ & 100 & - & - & 1 & & - & - \\
\hline & $>50$ & 44 & - & - & $\begin{array}{l}2.44 \\
(1.16-5.16)\end{array}$ & 0.019 & - & - \\
\hline
\end{tabular}

Abbreviations: ALL, acute lymphoblastic leukemia; B-ALL, B cells ALL; Cl, confidence interval; EFS, event-free survival; HR, hazard ratio; OS, overall survival; RFS, relapse-free survival; T-ALL, T cells ALL; TLC, total leukocyte count.

ancludes patients only if they have completed the respective phase of chemotherapy.

'factors taken for multivariate analysis.

(36-42 days); other factors such as gender, presenting white cell count, risk group, subtype, and treatment protocol were not associated with delay during induction (Supplementary Table S1, available online). A considerable number of patients had delay during subsequent phases of consolidation (65\%) and maintenance therapy (42\%), as shown in - Table 2.
The main causes for delay in intensive phase were febrile neutropenia (78\%), Grade 3 or 4 neutropenia (58\%), thrombocytopenia (32\%), abnormal liver function tests (17\%), and patient noncompliance (8\%). The major causes for delay in maintenance included febrile neutropenia (95\%), Grade 3 or 4 neutropenia (92\%), thrombocytopenia (39\%), liver toxicity 


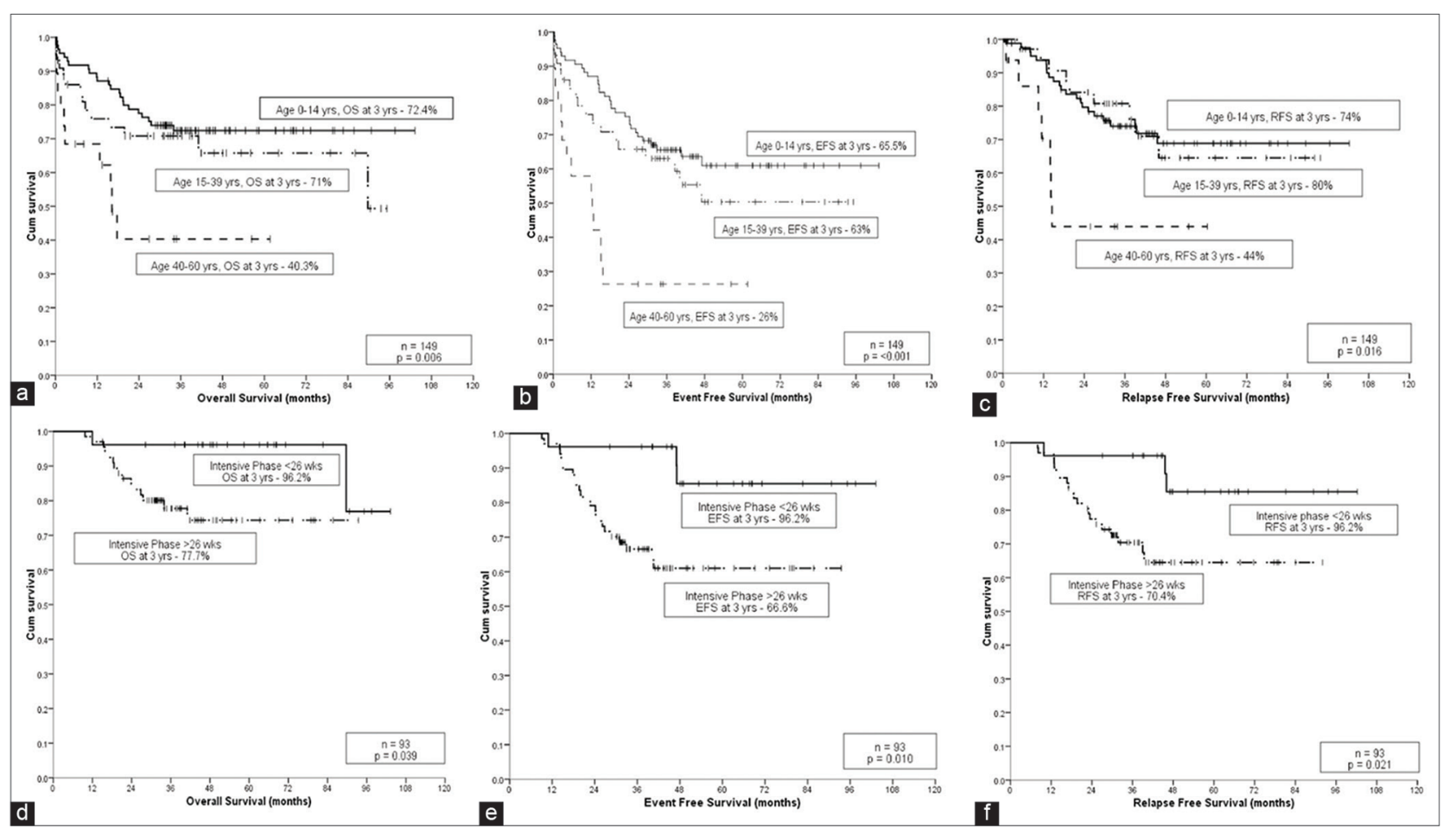

Fig. 1 Kaplan-Meier survival curve (A) overall survival, (B) event-free survival, (C) relapse-free survival for the entire cohort showing difference in survival outcomes between age groups (pediatric, adolescent and young adults, and adults); (D) overall survival, (E) event-free survival, (F) relapse-free survival for the Multi-center Protocol-841 cohort showing difference in survival outcome as per the duration of intensive phase of treatment of $<26$ or $>26$ weeks.

(56\%), and patient noncompliance (22\%). Multiple factors were concurrently affecting treatment delays. Grade of toxicities was not always available in the records; however, in the available data, mostly the interruption was for Grade 3 or 4 toxicities.

\section{Overall Outcomes}

Postinduction, 134 of the 149 (89.9\%) patients attained CR, whereas 12 patients (8\%) died during induction. In the entire cohort, 38 relapses were documented at different time points, of which 6 (15.8\%) were during consolidation, 24 (63.1\%) during maintenance, and 8 (21\%) during follow-up. Death without a documented relapse was seen in 13 patients $(9.7 \%$ out of 134 patients who attained CR). The median follow-up for the entire cohort was 41 months. Protocol-specific distribution of events and survival (EFS, RFS, and OS) outcomes is shown in -Table 3. For the entire cohort, EFS was $60 \%$, RFS $72 \%$, and OS was $68 \%$ at 3 years.

\section{Factors Affecting Survival Outcome}

Role of treatment delay during different phases of therapy in affecting survival outcomes in the entire cohort is shown in - Table 4. Delay in induction of $>42$ days adversely affected EFS (hazard ratio $[\mathrm{HR}]=1.78 ; 95 \%$ confidence interval $[\mathrm{Cl}]$, 1.01-3.14), while no significant difference was seen in RFS and OS. Patients with delay in intensive phase had significantly worse EFS and RFS with $\mathrm{HR}=2.43(95 \% \mathrm{CI}, 1.05-5.55)$ and $\mathrm{HR}=2.57$ (95\% CI, 1.05-6.29), respectively. Delay in maintenance therapy did not affect survival outcomes. However, in multivariate analysis, delay in any phase of treatment was not found to be independently affecting survival.

In the entire cohort, age and presenting white cell count were the only baseline factors independently affecting survival outcomes on multivariate analysis as shown in - Table $\mathbf{5}$. Kaplan-Meier survival curves with age-based outcomes for the entire cohort are shown in - Fig. 1A-C.

We did separate analysis for patients treated on MCP-841 ( $n=107)$, forming the largest cohort in our study. On multivariate analysis, delay in intensive phase significantly affected both EFS (HR $=3.85,95 \% \mathrm{CI}, 1.15-12.93$ ) and RFS $(\mathrm{HR}=3.42,95 \% \mathrm{Cl}, 1.09-11.60)$, whereas delay in consolidation significantly affected OS with $\mathrm{HR}=4.74(95 \% \mathrm{CI}$, 1.00-22.41), as shown in - Table 5. Kaplan-Meier survival curves showing the effect of delay in intensive therapy in the MCP-841 cohort are shown in - Fig. 1D-F.

\section{Discussion}

Treatment of childhood ALL is one of the great success stories in hemato-oncology, with long-term survival and cure rates of over $90 \%$ in the West. However, survival outcomes in developing countries with low-resource settings are significantly inferior; this disparity results from several causes such as lack of adequate treatment centers with expertise, socioeconomic constraints, belief in alternate medicine, heterogeneity in treatment intensity, and poor treatment compliance. ${ }^{13-16}$ In this study, we have shown that long interruptions 
Table 5 Cox regression univariate analysis: MCP-841 $(n=107)$

\begin{tabular}{|c|c|c|c|c|c|c|c|c|}
\hline \multirow[t]{2}{*}{ Parameters } & \multirow[t]{2}{*}{ Categories } & \multirow[t]{2}{*}{$n$} & \multicolumn{2}{|l|}{ EFS } & \multicolumn{2}{|l|}{ RFS } & \multicolumn{2}{|l|}{ OS } \\
\hline & & & $\mathrm{HR}(95 \% \mathrm{Cl})$ & $p$-Value & $\begin{array}{l}\text { HR } \\
(95 \% \mathrm{Cl})\end{array}$ & $p$-Value & $\begin{array}{l}\text { HR } \\
(95 \% \mathrm{Cl})\end{array}$ & p-Value \\
\hline \multicolumn{9}{|l|}{ Univariate analysis } \\
\hline \multirow[t]{2}{*}{ Age $(y)$} & $0-14$ & 79 & 1 & & 1 & & 1 & \\
\hline & $>15$ & 28 & $1.405(0.69-2.83)$ & 0.342 & $\begin{array}{l}1.127 \\
(0.45-2.82)\end{array}$ & 0.79 & $\begin{array}{l}1.56 \\
(0.70-3.47)\end{array}$ & 0.276 \\
\hline Sex & Male & 65 & 1 & & 1 & & 1 & \\
\hline \multirow[t]{3}{*}{$\operatorname{TLC}\left(\times 10^{9} / \mathrm{L}\right)(n=104)$} & Female & 42 & $0.686(0.35-1.36)$ & 0.281 & $\begin{array}{l}0.681 \\
(0.29-1.58)\end{array}$ & 0.372 & $\begin{array}{l}0.883 \\
(0.41-1.92)\end{array}$ & 0.753 \\
\hline & $<50$ & 72 & 1 & & 1 & & 1 & \\
\hline & $>50$ & 31 & $2.144(1.12-4.11)$ & 0.021 & $\begin{array}{l}2.518 \\
(1.13-5.59)\end{array}$ & 0.023 & $\begin{array}{l}1.867 \\
(0.87-4.03)\end{array}$ & 0.112 \\
\hline \multirow[t]{2}{*}{ Subtype } & B-ALL & 86 & 1 & & 1 & & 1 & \\
\hline & T-ALL & 21 & $1.167(0.53-2.60)$ & 0.699 & $\begin{array}{l}1.085 \\
(0.41-2.91)\end{array}$ & 0.87 & $\begin{array}{l}1.505 \\
(0.64-3.54)\end{array}$ & 0.35 \\
\hline \multirow[t]{2}{*}{ Risk } & Standard & 51 & 1 & & 1 & & 1 & \\
\hline & High & 56 & $1.94(1.00-3.75)$ & 0.049 & $\begin{array}{l}1.807 \\
(0.81-4.03)\end{array}$ & 0.148 & $\begin{array}{l}2.113 \\
(0.97-4.62)\end{array}$ & 0.061 \\
\hline \multirow[t]{2}{*}{ Delay in induction* (d) } & $\leq 42$ & 51 & 1 & & 1 & & 1 & \\
\hline & $>42$ & 49 & $2.474(1.20-5.10)$ & 0.014 & $\begin{array}{l}1.911 \\
(0.86-4.26)\end{array}$ & 0.113 & $\begin{array}{l}2.384 \\
(1.01-5.63)\end{array}$ & 0.048 \\
\hline \multirow[t]{2}{*}{ Delay in consolidation* (wk) } & $\leq 20$ & 27 & 1 & & 1 & & 1 & \\
\hline & $>20$ & 66 & $3.20(1.09-9.36)$ & 0.034 & $\begin{array}{l}2.82 \\
(0.95-8.37)\end{array}$ & 0.061 & $\begin{array}{l}4.73(1.00- \\
22.41)\end{array}$ & 0.049 \\
\hline \multirow[t]{2}{*}{ Delay in intensive phase* (wk) } & $\leq 26$ & 26 & 1 & & 1 & & 1 & \\
\hline & $>26$ & 67 & $\begin{array}{l}4.299 \\
(1.25-14.42)\end{array}$ & 0.018 & $\begin{array}{l}3.816 \\
(1.12- \\
12.95)\end{array}$ & 0.032 & $\begin{array}{l}4.599 \\
(0.97- \\
21.83)\end{array}$ & 0.055 \\
\hline \multirow[t]{2}{*}{ Delay in maintenance* (mo) } & $\leq 22$ & 37 & 1 & & 1 & & 1 & \\
\hline & $>22$ & 35 & $1.204(0.27-5.38)$ & 0.808 & $\begin{array}{l}1.216 \\
(0.27-5.44)\end{array}$ & 0.798 & $\begin{array}{l}2.198 \\
(0.19- \\
25.68)\end{array}$ & 0.53 \\
\hline \multicolumn{9}{|l|}{ Multivariate analysis } \\
\hline \multirow[t]{2}{*}{ Delay in intensive phase* (wk) } & $\leq 26$ & 26 & 1 & & 1 & & - & - \\
\hline & $>26$ & 67 & $3.85(1.1512 .93)$ & 0.029 & $\begin{array}{l}3.42(1.09- \\
11.60)\end{array}$ & 0.049 & - & - \\
\hline \multirow[t]{2}{*}{ Delay in consolidation* (wk) } & $\leq 20$ & 27 & - & - & - & - & 1 & \\
\hline & $>20$ & 66 & - & - & - & - & $\begin{array}{l}4.74(1.00- \\
22.41)\end{array}$ & 0.049 \\
\hline
\end{tabular}

Abbreviations: ALL, acute lymphoblastic leukemia; B-ALL, B cells ALL; CI, confidence interval; EFS, event-free survival; HR, hazard ratio; MCP-841, Multi-center Protocol-841; OS, overall survival; RFS, relapse-free survival; T-ALL, T cells ALL; TLC, total leukocyte count.

"Includes patients only if they have completed the respective phase of chemotherapy.

in treatment, due to any cause, mainly during the intensive phase, are associated with adverse survival in ALL.

The median age of patients in our study was 12 years (range, 1-57), with $30 \%$ patients having $>50 \times 10^{9} / \mathrm{L}$ total leukocyte at presentation and $32 \%$ diagnosed with T-ALL subtype. These numbers are consistent with other leukemia case series in India that report high TLC in 23 to $39 \%$ cases and T-ALL in 21 to $43 \%$ cases. $^{3-6}$ Induction mortality was $8 \%$, significantly higher than that of Western multicenter studies
$(1.1-2.2 \%)^{17,18}$ and Indian case series $(2-7 \%),{ }^{3-6}$ because of higher infection rates, with sepsis being the most common cause of induction mortality. CR was attained in $90 \%$ of patients. Of the total cases, $28 \%$ relapsed, with $63 \%$ of these relapses occurring during maintenance phase. Studies from developed countries have reported up to 15 to $20 \%$ relapse risk in ALL. ${ }^{19,20}$ In our study, conventional factors such as higher age at diagnosis and higher white cell count at presentation were independent predictors of poorer outcome 
for the entire cohort. Besides these conventional high-risk factors, delay in treatment mainly during the intensive phase was another main cause for high relapse and poorer outcomes in our study. Though treatment default is recognized to be an important impediment to ALL standard of care in developing nations, the impact of delays on outcome is still debated upon and there is limited data addressing this. Rate of noncompliance to treatment has varied from 2 to $20 \%$ in different series. $7,21,22$

Delay in initiation of induction therapy of $>7$ days after presentation to hospital was seen in $64 \%$ patients; however, this delay did not affect survival outcome in our study. In a study by Wahl et al, evaluating the role of weekend delay in initiation of chemotherapy for ALL, there was no significant difference in the measured outcomes of risk of relapse, death, and transfer to the intensive care unit for a mean delay of 4.13 \pm 2.40 days for patients admitted on weekends. ${ }^{23}$

We observed a significantly higher delay, though mild (36-42 days), in the pediatric age group (0-14 years) during induction therapy. This observation is counterintuitive to the common belief that adults and elderly should have more delay due to relatively poor tolerance to therapy and comorbidities. We presume that this could be due to poor nutritional status of the children at presentation. However, we do not have comprehensive records pertaining to baseline nutrition status for all patients in our retrospective dataset to support this explanation.

In the entire cohort in our study, delay in induction of $>42$ days adversely affected $\operatorname{EFS}(\mathrm{HR}=1.78, p=0.04)$, and delay in intensive phase (induction plus consolidation) had significantly worse EFS $(\mathrm{HR}=2.41, p=0.03)$ and $\mathrm{RFS}(\mathrm{HR}=2.57$, $p=0.03$ ). However, these were not independent predictors of outcome in multivariate analysis and no significant difference was seen in OS due to treatment delays. Nonetheless, in patients treated on MCP-841 (largest cohort in our study), treatment delays were found to be independent predictors of worse survival outcomes in multivariate analysis; delay in intensive phase had poorer EFS (HR = 3.85, $p=0.02$ ) and RFS $(\mathrm{HR}=3.42, p=0.04)$, whereas delay in consolidation phase had significantly worse OS (HR $=4.74, p=0.04)$. In a report by Suarez et al, on the effect of a twinning program, significant reduction in treatment-related mortality and treatment abandonment rate was seen; however, the relapse rate was still high due to inappropriate treatment delays ( $>4$ weeks) that strongly predicted treatment failure and markedly inferior disease-free survival. ${ }^{13}$ In another study by Kumar et al, analyzing the delay in postremission chemotherapy in adults with newly diagnosed ALL on the ECOG 2993/UKALLXII trial protocol, very long delay ( $>4$ weeks) at the start of intensification phase adversely affected EFS (HR $=1.4, p=0.02)$ and $\mathrm{OS}(\mathrm{HR}=1.4, p=0.03)$ in patients undergoing allografting. ${ }^{9}$ In a study from Hyderabad, India, by Arigela et al, utilizing MCP-841 as the treatment protocol and analyzing the impact of insurance-based health-care system and treatment compliance on the outcome, poor treatment compliance was seen in up to $41 \%$ of patients and it adversely affected OS. ${ }^{14} \mathrm{On}$ the contrary, Laughton et al, in a study from Australia, did not find any significant association between delay during induction or consolidation treatments and risk of subsequent relapse. ${ }^{24}$ Similarly, in another study from Turkey by Koka et al, when total delay time was analyzed in each patient, individuals who experienced less treatment withdrawal were found to have statistically significantly poorer OS and EFS when compared with patients with longer than 10 days of treatment cessation ( $p<0.0001$ for both OS and EFS). ${ }^{25}$ They hypothesized that the reason for this paradoxical observation may be that patients with lesser delays have suboptimal exposure to chemotherapy and hence less early toxicity to cause treatment interruption. ${ }^{25}$

Some other studies that have primarily evaluated treatment compliance and interruptions during maintenance chemotherapy of ALL have suggested conflicting results. Some reports have confirmed that lower adherence is related to increased relapse risk independent of other factors such as ethnicity, ${ }^{7}$ whereas other studies have validated lower relapse rates and better survival in patients with longer treatment interruptions, with a hypothesis that interruptions reflect toxicities and thereby preservation of dose intensity, which is equally essential for desired treatment outcomes. ${ }^{8,21}$ In a retrospective study by Yeoh et al, evaluating treatment delay and the risk of relapse in 141 pediatric ALL patients, no significantly higher risk of relapse was found with longer delays during the total length of treatment or during the intensive phase. Conversely, a tendency for fewer relapses in the group with longer treatment delays during maintenance therapy was found. ${ }^{8}$ In another report by de Oliveira et al, from Brazil, $19 \%$ of patients unduly interrupted chemotherapy during maintenance, but, EFS was higher for children with chemotherapy delays due to toxicities, suggesting that the intensity of maintenance chemotherapy may not have been enough to achieve adequate myelosuppression, an indicator of 6-MP efficacy, in patients without delay and toxicities. ${ }^{21}$ We did not find any association between delay during maintenance and survival outcomes; however, the number of patients completing maintenance was small and follow-up was short. Thus, though the data are conflicting, largely we conclude that inadvertent delays in treatment delivery will affect long-term outcomes to a variable extent.

Treatment-related toxicities and patient's noncompliance remain the main cause of delay in patients on ALL therapy. We found that these delays were more common in the intensive phase rather than in the maintenance phase $(42 \%$ in maintenance against $65 \%$ in consolidation and $52 \%$ in induction), which reflected in the higher rates of relapse seen in the maintenance phase. Major causes for delay included febrile neutropenia, Grade 3 or 4 neutropenia, thrombocytopenia, hepatotoxicity, and patient noncompliance, with each factor contributing to different extents in different phases. However, patient noncompliance was more common in the maintenance phase $(22 \%)$ than during the intensive phase (6\%). Though transaminitis of $>5$ times the upper limit of normal is defined as Grade 3, it does not warrant dose modification or drug withdrawal during maintenance with 6-MP and methotrexate, unless accompanied by hyperbilirubinemia. Unnecessary treatment interruptions for minor toxicities outside that prescribed by the protocol should be avoided by 
health-care professionals and counseling to ensure patient compliance should be strengthened throughout the treatment course, more importantly during maintenance as the patient and family sometimes physicians too may misapprehend the intensity to be maintained when therapy is shifted to oral drugs. ${ }^{26,27}$

Poor socioeconomic status and malnutrition are independent risk factors for poorer outcome in low-income countries, irrespective of the biology of ALL. ${ }^{15,16}$ These factors are also the major contributors for nonadherence to treatment, though in our retrospective study we have not separately analyzed these factors in affecting delay and outcomes. Nevertheless, holistic treatment approach inclusive of psychosocial care and support from dedicated nongovernmental organizations can help mitigate some of these modifiable factors. To reduce treatment duration and burden among poor families in low-income countries, a prospective randomized study from Brazil showed that reducing maintenance duration by 6 months from 24 to 18 months did not affect overall outcome. ${ }^{28}$ Similar adaptation of treatment protocol and practices to local conditions done in a systematic way and with evidence can also improve overall outcomes of ALL in resource-limited settings.

Some of the limitations of our study were the retrospective nature with significant missing data in some areas, small number of patients, short follow-up, especially for patients completing maintenance, and heterogeneity of patient population and treatment protocols. In addition, modern risk factors such as genetic and molecular characteristics, and minimal residual disease, were not available uniformly for a significant number of patients and hence were not analyzed. Further, we could not determine the effect of reasons of interruptions on outcome, and also it remains unclear whether treatment delays are a cause of worse outcome or whether they are just associated with adverse survival. Furthermore, our results are with clinically defined cutoff in different phases, and it cannot be ascertained what is the acceptable period of interruption and what should be the optimal cutoff for same. Nonetheless, our study contributes to the limited data in literature, especially from India, on the association of treatment interruptions and clinical outcomes during the protracted treatment course of ALL.

Even though the available literature data are divided on the role of treatment interruptions in affecting outcomes in ALL, we conclude that long and unwarranted treatment delays mostly in the intensive phase are associated with adverse survival outcomes in ALL, especially in pediatric, adolescent, and young adult patients. All attempts should be made by health-care workers, patients, and their caregivers to maintain the protocol-defined treatment intensity while adequately managing toxicities, for long-term favorable outcomes.

\section{Conflicts of Interest}

None declared.

\section{Acknowledgments}

We acknowledge the help of medical records staff in the Department of Medical Oncology in retrieving the case files for data collection.

\section{References}

1 Hunger SP, Lu X, Devidas M, et al. Improved survival for children and adolescents with acute lymphoblastic leukemia between 1990 and 2005: a report from the children's oncology group. J Clin Oncol 2012;30(14):1663-1669

2 Goldstone AH, Richards SM, Lazarus HM, et al. In adults with standard-risk acute lymphoblastic leukemia, the greatest benefit is achieved from a matched sibling allogeneic transplantation in first complete remission, and an autologous transplantation is less effective than conventional consolidation/maintenance chemotherapy in all patients: final results of the International ALL Trial (MRC UKALL XII/ECOG E2993) Blood 2008;111(4):1827-1833

3 Radhakrishnan V, Gupta S, Ganesan P, et al. Acute lymphoblastic leukemia: A single center experience with Berlin, Frankfurt, and Munster-95 protocol. Indian J Med Paediatr Oncol 2015;36(4):261-264

4 Bajel A, George B, Mathews V, et al. Treatment of children with acute lymphoblastic leukemia in India using a BFM protocol. Pediatr Blood Cancer 2008;51(5):621-625

5 Malhotra P, Varma S, Varma N, et al. Outcome of adult acute lymphoblastic leukemia with BFM protocol in a resource-constrained setting. Leuk Lymphoma 2007;48(6):1173-1178

6 Ganesan P, Sagar TG, Kannan K, et al. Acute lymphoblastic leukemia in young adults treated with intensive "pediatric" type protocol. Indian J Hematol Blood Transfus 2018;34(3):422-429

7 Bhatia S, Landier W, Shangguan M, et al. Nonadherence to oral mercaptopurine and risk of relapse in Hispanic and non-Hispanic white children with acute lymphoblastic leukemia: a report from the children's oncology group. J Clin Oncol 2012;30(17):2094-2101

8 Yeoh A, Collins A, Fox K, et al. Treatment delay and the risk of relapse in pediatric acute lymphoblastic leukemia. Pediatr Hematol Oncol 2017;34(1):38-42

9 Kumar AJ, Gimotty PA, Gelfand JM, et al. Delays in postremission chemotherapy for Philadelphia chromosome negative acute lymphoblastic leukemia are associated with inferior outcomes in patients who undergo allogeneic transplant: an analysis from ECOG 2993/MRC UK ALLXII. Am J Hematol 2016;91(11):1107-1112

10 Arya LS, Kotikanyadanam SP, Bhargava M, et al. Pattern of relapse in childhood ALL: challenges and lessons from a uniform treatment protocol. J Pediatr Hematol Oncol 2010;32(5):370-375

11 Gökbuget N, Hoelzer D, Arnold R, et al. Treatment of Adult ALL according to protocols of the German Multicenter Study Group for Adult ALL (GMALL) Hematol Oncol Clin North Am 2000;14(6):1307-1325, ix

12 Möricke A, Reiter A, Zimmermann M, et al. German-AustrianSwiss ALL-BFM Study Group. Risk-adjusted therapy of acute lymphoblastic leukemia can decrease treatment burden and improve survival: treatment results of 2169 unselected pediatric and adolescent patients enrolled in the trial ALL-BFM 95. Blood 2008;111(9):4477-4489

13 Suarez A, Piña M, Nichols-Vinueza DX, et al. A strategy to improve treatment-related mortality and abandonment of therapy for childhood ALL in a developing country reveals 
the impact of treatment delays. Pediatr Blood Cancer 2015;62(8):1395-1402

14 Arigela RS, Gundeti S, Ganta RR, Nasaka S, Linga VG, Maddali LS. Trends in management of acute lymphoblastic leukemia: Influence of insurance based healthcare and treatment compliance on the outcome of adolescents and adults with acute lymphoblastic leukemia. Indian J Med Paediatr Oncol 2016;37(1):32-37

15 Viana MB, Fernandes RA, de Oliveira BM, Murao M, de Andrade Paes C, Duarte AA. Nutritional and socio-economic status in the prognosis of childhood acute lymphoblastic leukemia. Haematologica 2001;86(2):113-120

16 Gupta S, Wilejto M, Pole JD, Guttmann A, Sung L. Low socioeconomic status is associated with worse survival in children with cancer: a systematic review. PLoS One 2014;9(2):e89482

17 Prucker C, Attarbaschi A, Peters C, et al. Austrian BerlinFrankfurt-Münster (BFM) Study Group. Induction death and treatment-related mortality in first remission of children with acute lymphoblastic leukemia: a population-based analysis of the Austrian Berlin-Frankfurt-Münster study group. Leukemia 2009;23(7):1264-1269

18 Seif AE, Fisher BT, Li Y, et al. Patient and hospital factors associated with induction mortality in acute lymphoblastic leukemia. Pediatr Blood Cancer 2014;61(5):846-852

19 Teachey DT, Hunger SP. Predicting relapse risk in childhood acute lymphoblastic leukaemia. $\mathrm{Br} \mathrm{J}$ Haematol 2013;162(5):606-620

20 Ceppi F, Cazzaniga G, Colombini A, Biondi A, Conter V. Risk factors for relapse in childhood acute lymphoblastic leukemia: prediction and prevention. Expert Rev Hematol 2015;8(1):57-70
21 de Oliveira BM, Valadares MT, Silva MR, Viana MB. Compliance with a protocol for acute lymphoblastic leukemia in childhood. Rev Bras Hematol Hemoter 2011;33(3):185-189

22 Lancaster D, Lennard L, Lilleyman JS. Profile of non-compliance in lymphoblastic leukaemia. Arch Dis Child 1997;76(4):365-366

23 Wahl SK, Gildengorin G, Feusner J. Weekend delay in initiation of chemotherapy for acute lymphoblastic leukemia: does it matter? J Pediatr Hematol Oncol 2012;34(1):e8-e11

24 Laughton SJ, Ashton LJ, Kwan E, Norris MD, Haber M, Marshall GM. Early responses to chemotherapy of normal and malignant hematologic cells are prognostic in children with acute lymphoblastic leukemia. J Clin Oncol 2005;23(10):2264-2271

25 Koka A, Saygin C, Uzunaslan D, Ozdemir N, Apak H, Celkan T. A 17-year experience with ALL-BFM protocol in acute lymphoblastic leukemia: prognostic predictors and interruptions during protocol. Leuk Res 2014;38(6):699-705

26 Sitaresmi MN, Mostert S, Gundy CM, Sutaryo, Veerman AJ. Health-care providers' compliance with childhood acute lymphoblastic leukemia protocol in Indonesia. Pediatr Blood Cancer 2008;51(6):732-736

27 Peeters M, Koren G, Jakubovicz D, Zipursky A. Physician compliance and relapse rates of acute lymphoblastic leukemia in children. Clin Pharmacol Ther 1988;43(3):228-232

28 Brandalise SR, Viana MB, Pinheiro VR, et al. Shorter maintenance therapy in childhood acute lymphoblastic leukemia: The experience of the prospective, Randomized Brazilian GBTLI ALL-93 protocol. Front Pediatr 2016;4:110 